\title{
Flow Assurance in Heavy Oil Production
}

\author{
John Ratulowski* \\ "DBR Technology Center, Schlumberger, Edmonton, Canada.
}

Flow assurance activities look to address a variety of fluid property issues that may impact the planned flow of gas, oil, and water through the production system. In the case of heavy oils, the primary issues that facility designers and operators need to address include 1) the effects of the high viscosity and strong temperature dependence of viscosity on the transport of heavy oils, 2) the effects on slow gas separation and strong emulsion stability on separator design and operations, and 3) the potential for asphaltene precipitation due to the incompatibility of light oils or diluents that are blended with heavy oil streams. In the case of tar mat formation, the formation of these layers within the reservoir may be an indication of asphaltene precipitation from the overlying conventional oil. Subsequent production of this conventional oil introduces the potential for issues related to depressurization driven asphaltene precipitation and deposition. All of these potential flow assurance issues will be addressed during this discussion. 